\title{
Maternal depression and malnutrition in children in southwest Uganda: a case control study
}

\author{
Scholastic Ashaba ${ }^{1 *}$, Godfrey Zari Rukundo ${ }^{1}$, Florence Beinempaka ${ }^{2}$, Moses Ntaro ${ }^{3}$ and John C. LeBlanc ${ }^{4}$
}

\begin{abstract}
Background: Malnutrition remains one of the most significant child health problems in developing countries with an estimated $53 \%$ of child deaths per year attributed to being underweight. The 2011 Uganda Demographic and Health Survey (UDHS) showed that $38 \%$ of the children were stunted and $16 \%$ were underweight. While dietary and environmental factors are known major contributors to children's nutritional status, maternal depression may also contribute since it disrupts the mothers' ability to cope with demands of childcare. This study aimed to determine the association between maternal depression and malnutrition in children aged one to 5 years in southwest Uganda.

Methods: The study was undertaken between October and December 2014 on children aged one to 5 admitted to the Mbarara regional referral hospital. Cases were malnourished children and controls were children with other chronic conditions but normal nutritional status admitted to the same hospital. Children's ages were recorded, weight and height taken and converted into height for age, weight for height and weight for age and malnutrition was determined based on WHO child growth standards. Mothers of both groups of children were assessed for depression using the depression module of the Mini International Neuropsychiatric Interview (MINI). Participants provided informed consent prior to enrollment. The study was approved by Mbarara University of Science and Technology Research Ethics Committee and funded by MicroResearch.

Results: All 166 mothers who were approached agreed to participate in the study. The prevalence of depression among mothers of malnourished children (86 cases) was $42 \%$ compared to $12 \%$ among mothers of controls (86 controls). The mean age was 25 years (SD 4.43, range 18-40 years). The majority (75\%) were married and most were peasant farmers (62\%). Maternal depression was significantly associated with malnutrition in children with a crude odds ratio of 2.23 (1.08-1.89) and an adjusted odds ratio of $2.4(1.11-5.18)$.
\end{abstract}

Conclusion: Maternal depression impacts negatively on child nutrition and development as shown by a higher prevalence of depression among mothers of malnourished children compared to the control group. Routine screening and treatment for depression should be included in all maternal and child health clinics.

Keywords: Maternal depression, Malnutrition, Children under five years

\footnotetext{
*Correspondence: ashaba.schola@gmail.com

'Department of Psychiatry, Mbarara University of Science and Technology,

Mbarara, Uganda

Full list of author information is available at the end of the article
} 


\section{Background}

Malnutrition remains one of the most significant child health problems in developing countries with an estimated $53 \%$ of child deaths per year being attributed to being underweight. Globally, it is estimated that there are nearly 20 million children who are severely and acutely malnourished [1] and most of these children live in south Asia and Sub-Saharan Africa. Child growth studies in 139 countries revealed that $20 \%$ of children below 5 years in low-income and middle-income countries were malnourished [2]. In addition, WHO estimates indicate that approximately $16 \%$ of children from developing countries are severely malnourished basing on a cut off for weight for height, weight for age, and height for age of below -3 standard deviations (-3SD) of the WHO child growth standards [3].

Malnutrition impairs physical growth, increases morbidity and mortality and reduces cognitive development, fertility and physical work capacity [4]. Malnutrition is also an underlying risk factor that increases the morbidity and mortality of many diseases in children and adults [5]. More than 200 million children under the age of 5 years fail to reach their growth and cognitive potential due to lack of adequate nutrition and deficient care [6].

Although dietary and environmental factors play a major role in children's nutritional status [7], maternal mental health has been shown to play a major contributing role [8], possibly by interfering with the mother's responsibility for child care [9]. Poor maternal mental health, in particular maternal depression has been pointed out as a risk factor for poor growth in young children [10] and infants of mothers with depression have been found to be at a greater risk of growth failure than are infants whose mothers are not depressed [11, 12]. In Uganda, the prevalence of depression in women is estimated to be $27-31 \%$ [13]. A study by Rahman and colleagues [10] estimated that reductions in the prevalence of maternal depression could lead to a reduction in impaired child growth of up to $30 \%$. Sadly, maternal mental health is still largely neglected as a component in child health programs in developing countries. The much touted integrated management of childhood illness strategy by World Health Organization does not even mention maternal mental health [14].

There are no published studies in Uganda about a possible association between maternal depression and malnutrition despite national surveys indicating that malnutrition in children under five is very rampant especially in southwest Uganda [15]. The main aim of this study was to assess the relationship between maternal depression and malnutrition in children aged one to 5 years in southwest Uganda.

\section{Methods}

We undertook a case-control study between October and December 2014 at the Mbarara Regional Referral Hospital in southwest Uganda.

\section{Inclusion and exclusion criteria}

Children were considered for the study if they were aged one to 5, their mothers were at least 18 years old and their mothers were the primary caregiver of the child during the admission. Cases had malnutrition as defined in the World Health Organization (WHO) child growth standard measurements [16]. The exclusion criterion for cases was a significant comorbid illness identified through investigations done while in hospital. Inclusion criteria for controls were being admitted for a chronic physical illness but having normal nutritional status. Controls were matched to cases according to the child's age (within 6 months) and gender.

\section{Measurements \\ Children anthropometry}

Children's weight, height and mid upper arm circumference (MUAC) were taken following standard anthropometric procedures [17] and their ages were determined by maternal report. Anthropometric measures were converted into height for age, weight for height and weight for age and children were considered to be malnourished if their $\mathrm{Z}$ scores were below minus three standard deviations (-3SD) and had a MUAC of less than $115 \mathrm{~mm}$ according to WHO growth standard measurements [16].

\section{Depression among mothers}

Following consent, the mothers of both cases and controls were assessed for current depression using the depression module of the Mini International Neuropsychiatric interview (M.I.N.I.) [18]. The MINI is a brief structured interview for major axis I Psychiatric disorders in DSM-IV and ICD-10 [18] that can be administered in about 15 minutes by a clinician after a brief training. The depression module of the Mini International neuropsychiatric interview [18] was selected because it is superior to screening tools that have been used in other similar studies [19-21]. Moreover, the depression module of the MINI has been translated into local languages and used in different parts of Uganda in different contexts [22-25]. We asked mothers two screening questions: 1) feeling sad most of the day almost every day for two weeks, and 2) loss of interest in activities previously enjoyed. If a participant answered yes to one of these, more questions about depression symptoms were asked including change in appetite, trouble sleeping, feeling tired most of the time, feeling worthless, difficulty with concentration and having suicidal feelings. If a participant answered yes to five or more of the above questions they were considered depressed. 
Two trained psychiatric nursing officers did data collection. Participants who screened positive for depression were referred for treatment in the hospital's mental health unit.

\section{Sample size determination}

Sample size was determined using OpenEpi software version 3.03.17 assuming a two-sided significance level (alpha or $\alpha$ ) of 0.05 and a power of $80 \%$, and assuming that $20 \%$ of controls had depression compared to $40 \%$ of cases. This gave us a total sample of 83 cases and 83 controls.

\section{Ethical approval and funding}

The study was approved by the Research and Ethics Committee (REC) of Mbarara University of Science and Technology and funded by a MicroResearch grant (www.microresearch.ca). We sought informed consent from the participating mothers.

\section{Data analysis}

Data were inspected and data entry errors were removed. Data were analyzed using SPSS version 18. Binary variables were summarized as percentages of cases and controls with the attribute (e.g., depressed yes/no). We analyzed group differences on variables using a chi square test. Odds ratios (OR) and $95 \%$ confidence intervals $(\mathrm{CI})$ were determined using logistic regression analysis with the dependent variable being case/control status and the independent variables being mother depressed at the time of admission, age, marital status, education attained, occupation, source of income and number of children. Results were considered significant if the p-value was $\leq 0.05$. First, we used bivariate logistic regression analysis to estimate OR for each variable. Those that demonstrated an association with the outcome were inserted into a multiple logistic regression model to estimate the adjusted OR of association between maternal depression and malnutrition in children.

Table 1 Socio-demographic characters of the mothers (cases and controls)

\begin{tabular}{|c|c|c|c|c|}
\hline \multirow[t]{3}{*}{ Variables } & \multicolumn{2}{|c|}{ Malnutrition in children } & \multirow[t]{3}{*}{ Total (\%) } & \multirow{3}{*}{$X^{2}(p \text {-value })^{*}$} \\
\hline & Cases $(n=83)$ & Controls $(n=83)$ & & \\
\hline & Proportion (\%) & Proportion (\%) & & \\
\hline \multicolumn{5}{|l|}{ Mother's age } \\
\hline $18-24$ & $41(25 \%)$ & $36(22 \%)$ & 77 (47 \%) & \multirow[t]{3}{*}{$1.29(0.53)$} \\
\hline $25-30$ & $26(16 \%)$ & $33(20 \%)$ & $59(36 \%)$ & \\
\hline$>30$ & $16(10 \%)$ & $14(8 \%)$ & $30(18 \%)$ & \\
\hline \multicolumn{5}{|l|}{ Mother's marital status } \\
\hline Married & $60(36 \%)$ & 65 (39\%) & $125(75 \%)$ & \multirow[t]{2}{*}{$0.81(0.37)$} \\
\hline Single/Separated/widowed & $23(14 \%)$ & $18(11 \%)$ & $41(25 \%)$ & \\
\hline \multicolumn{5}{|l|}{ Mother's level of education } \\
\hline Lower primary (p1-p4) & $33(20 \%)$ & 19 (11\%) & $52(31 \%)$ & \multirow[t]{3}{*}{$5.53(0.06)$} \\
\hline Upper primary (p5-p7) & 35 (21\%) & $46(28 \%)$ & 81 (49 \%) & \\
\hline High school or more & $15(9 \%)$ & 18 (11\%) & $33(20 \%)$ & \\
\hline \multicolumn{5}{|l|}{ Mother's occupation } \\
\hline Peasant farmer & 57 (34 \%) & $46(28)$ & $104(63 \%)$ & \multirow[t]{3}{*}{$4.27(0.12)$} \\
\hline Retail business & $13(8 \%)$ & $24(15 \%)$ & 37 (22 \%) & \\
\hline Casual labor/no occupation & $13(8 \%)$ & $12(7 \%)$ & $25(15 \%)$ & \\
\hline \multicolumn{5}{|l|}{ Mother's source of income } \\
\hline Farming & $48(29 \%)$ & 37 (22 \%) & 85 (57 \%) & \multirow[t]{3}{*}{$3.70(0.16)$} \\
\hline Retail business & $21(13 \%)$ & $32(19)$ & $53(32 \%)$ & \\
\hline Casual laborer/no source of income & $14(5 \%)$ & $14(5 \%)$ & $28(10 \%)$ & \\
\hline \multicolumn{5}{|l|}{ Number of children } \\
\hline $1-2$ & $44(27 \%)$ & $43(26 \%)$ & 87 (53\%) & \multirow[t]{3}{*}{$0.40(0.82)$} \\
\hline $3-4$ & $26(16 \%)$ & $24(14 \%)$ & $50(30 \%)$ & \\
\hline$>4$ children & $13(9 \%)$ & $16(10 \%)$ & $29(18 \%)$ & \\
\hline
\end{tabular}

$* p \leq 0.05$ 


\section{Results}

Eighty-three cases and 83 controls were recruited between October and December 2014. The prevalence of depression was $42 \%$ among mothers of malnourished children (cases) compared to $12 \%$ among mothers of controls. The average age of the participants was 25 years (SD 4.4, range 18-40 years). The majority of the mothers (75\%) were married and $63 \%$ were peasant farmers. There were no statistically significant differences between controls and cases (Table 1). Of the malnourished children $75 \%$ were stunted (low height for age), $84 \%$ were wasted (low weight for height) while $87 \%$ were underweight (low weight for age) (Table 2). Bivariate logistic regression analysis showed a strong association between malnutrition in children and maternal depression (Table 3). This remained significant in a multivariate logistic regression OR $2.4(1.11-5.18)$ (Table 4) that also included all other covariates. This study also found an association between low maternal education and malnutrition in children one to five years of age during bivariate analysis but this association was explained away by other factors in the multivariate model.

\section{Discussion}

For the first time in an African setting, we have demonstrated an association between maternal depression and malnutrition in children aged one to 5. This confirms findings in other low and high-income countries including studies in Jamaica, Pakistan, India and the United Kingdom [11, 19-21, 26, 27]. Infants of depressed mothers are likely to be underweight and stunted compared to children of mothers without depression [20, 21, 28]. The association between maternal depression and malnutrition persisted after controlling for education, family size, and source of income.

Maternal depression may contribute to under nutrition in children by having a negative impact on interpersonal behaviour and parenting as well as impairment in social functioning associated with most psychiatric disorders [29]. Maternal depression not only reduces maternal interest in a child [27] but also impairs a woman's ability to cope with the responsibilities of being a mother. This leads to an inability to provide a healthful diet for the child [30]. Maternal depression reduces a mother's involvement in maternal care, which impairs physical growth of the child [20,31]. Mothers with depression

Table 2 Anthropometric measurements of children (cases)

\begin{tabular}{lll}
\hline Variables & $\begin{array}{l}(N=83) \\
\text { proportion }\end{array}$ & $\begin{array}{l}\text { Percentage } \\
(\%)\end{array}$ \\
\hline Stunted (below -3SD height for age) & 62 & $75 \%$ \\
Underweight (below -3SD weight for age) & 72 & $87 \%$ \\
Wasted (below -3SD weight for height) & 69 & $83 \%$ \\
\hline
\end{tabular}

Table 3 Maternal depression and other socio-demographic factors associated with malnutrition in children

\begin{tabular}{|c|c|c|}
\hline Variables & Unadjusted OR (95 \% Cl) & $P$-value ${ }^{*}$ \\
\hline \multicolumn{3}{|l|}{ Depression in the mother } \\
\hline Depression & $2.4(1.18-4.79)$ & $0.015^{*}$ \\
\hline \multicolumn{3}{|l|}{ Age of the mother (years) } \\
\hline \multicolumn{3}{|l|}{$18-24^{\mathrm{a}}$} \\
\hline $25-30$ & $1.2(0.61-2.52)$ & 0.558 \\
\hline$>30$ & $1.2(0.50-2.91)$ & 0.680 \\
\hline \multicolumn{3}{|l|}{ Level of education of the mother } \\
\hline \multicolumn{3}{|l|}{ Lower Primary $(\mathrm{p} 1-\mathrm{p} 4)^{\mathrm{a}}$} \\
\hline Upper Primary (p5-p7) & $2.4(1.48-7.61)$ & 0.004 \\
\hline Secondary school (s1-s6) & $2.4(0.89-6.45)$ & 0.084 \\
\hline \multicolumn{3}{|l|}{ Marital status } \\
\hline \multicolumn{3}{|l|}{ Married $^{a}$} \\
\hline Single/separated/widowed & $0.9(0.43-1.89)$ & 0.799 \\
\hline \multicolumn{3}{|l|}{ Occupation of the mother } \\
\hline \multicolumn{3}{|l|}{ Peasant farmer ${ }^{a}$} \\
\hline Retail business & $1.6(0.76-3.54)$ & 0.209 \\
\hline Casual laborer/no occupation & $1.2(0.49-3.02)$ & 0.683 \\
\hline \multicolumn{3}{|l|}{ Mother's Source of income } \\
\hline \multicolumn{3}{|l|}{ Farming $^{a}$} \\
\hline Retail business & $2.0(0.73-5.47)$ & 0.177 \\
\hline Casual labor/no source of income & $2.6(0.90-7.48)$ & 0.076 \\
\hline \multicolumn{3}{|l|}{ Number of children } \\
\hline \multicolumn{3}{|l|}{$1-2^{a}$} \\
\hline $3-4$ & $0.9(0.40-1.81)$ & 0.688 \\
\hline$>4$ & $1.9(0.79-4.38)$ & 0.152 \\
\hline
\end{tabular}

tend to be less responsive towards their children [29] and are less likely to form a secure attachment with their children [32] which may also contribute to neglect of maternal nurturing roles.

This study found no association between maternal level of education and malnutrition in children one to five years. This is inconsistent with other studies [28, 33, 34]. Gwatkin and colleagues found high levels of malnutrition among children of less educated women in developing countries [33] while Reed and colleagues found higher level of education to be associated with improved child weight for age in Benin, West Africa [34]. The studies that have found an association between maternal low level of education and malnutrition in children indicate that mothers with low education tend to live in rural areas with more limited nutritional knowledge and health access [35]. It has been argued that education empowers women, influencing their capacity to make decisions [28] concerning children's nutrition and access to health services [36]. 
Table 4 Adjusted factors associated with malnutrition in children

\begin{tabular}{|c|c|c|}
\hline Variable & Adjusted OR (95\% Cl) & $P$-value* \\
\hline Maternal depression & $2.4(1.11-5.18)$ & $0.03^{*}$ \\
\hline \multicolumn{3}{|l|}{ Age of the mother (years) } \\
\hline \multicolumn{3}{|l|}{$18-24^{\mathrm{a}}$} \\
\hline $25-30$ & $0.9(0.36-2.44)$ & 0.88 \\
\hline$>30$ & $0.6(0.15-2.54)$ & 0.50 \\
\hline \multicolumn{3}{|l|}{ Mothers' level of education } \\
\hline \multicolumn{3}{|l|}{ Lower primary (p1-p4) } \\
\hline Upper primary (p5-p6) & $0.5(0.15-1.34)$ & 0.15 \\
\hline Secondary education (s1-s6) & $1.3(0.50-3.30)$ & 0.59 \\
\hline \multicolumn{3}{|l|}{ Marital status } \\
\hline \multicolumn{3}{|l|}{ Married $^{a}$} \\
\hline Single/separated/widowed & $1.4(0.60-3.20)$ & 0.44 \\
\hline \multicolumn{3}{|l|}{ Occupation of the mother } \\
\hline \multicolumn{3}{|l|}{ Peasant farmer ${ }^{a}$} \\
\hline Retail business & $1.1(0.18-6.54)$ & 0.93 \\
\hline Casual laborer/no occupation & $1.3(0.29-6.08)$ & 0.72 \\
\hline \multicolumn{3}{|l|}{ Source of income } \\
\hline \multicolumn{3}{|l|}{ Farming $^{\mathrm{a}}$} \\
\hline Retail business & $2.3(0.64-8.30)$ & 0.20 \\
\hline Casual labor/no source of income & $2.2(0.46-10.2)$ & 0.33 \\
\hline \multicolumn{3}{|l|}{ Number of children } \\
\hline \multicolumn{3}{|l|}{$1-2^{a}$} \\
\hline $3-4$ & $1.2(0.42-3.25)$ & 0.77 \\
\hline$>4$ & $2.7(0.72-10.4)$ & 0.41 \\
\hline
\end{tabular}

Educated women are able to make better health choices for their children as well as having more knowledge about good child nutrition and feeding practices [37].

Our study has limitations. It was a hospital-based study making it difficult to generalize the results to the general population. The study was cross sectional and hence it is difficult to tease out the cause -effect relationship between maternal depression and malnutrition in children.

However, given that, the control children had chronic illness but not malnutrition helps mitigate that bias. That $12 \%$ percent of these control mothers had depression is not surprising but this was much less than the $42 \%$ amongst mothers of hospitalized malnourished children. The fact that the study was carried out in the hospital setting could have contributed to emotional distress associated with the children's sickness in both groups. A survey in the community in southwestern Uganda would be very important to see if the same association exists.

\section{Conclusion}

This study shows that maternal depression in mothers of young children is very common and is linked to malnutrition. All maternal newborn and childcare comprehensive programs aimed at improving health outcomes need to address this important mental illness for its own sake as well as the likely outcome that depressed mothers will provide inadequate care and diets for their children.

Competing interest

The authors declare that they have no competing interest.

\section{Authors' contributions}

SA participated in the design of the study, statistical analysis, and manuscript preparation. GZR participated in the study design, statistical analysis, and manuscript preparation. FB participated in data collection and contributed to manuscript preparation. MN participated in design of the study and contributed to manuscript preparation. JCL was instrumental in the design of the study, statistical analysis, and manuscript preparation. All authors read and approved the manuscript.

\section{Authors' information}

SA is a senior lecturer in the department of Psychiatry and the Coordinator of the MicroResearch project in the Faculty of Medicine Mbarara University of Science and Technology. SA also serves as a member of the Faculty Research committee in the University.

GZR is a senior lecturer and head of department of Psychiatry and

Chairperson Quality Assurance committee, Mbarara University of Science and Technology.

MN is the Coordinator of Community Based Education Research and Service (COBERS) at Mbarara University of Science and Technology.

FB is a lecturer and head of department of nursing Mbarara University of Science and Technology.

$\mathrm{JCL}$ is an Associate Professor of Pediatrics, Psychiatry and Community Health and Epidemiology Dalhousie University and a mentor at MicroResearch Canada.

\section{Acknowledgements}

We acknowledge the mothers who accepted to take part in the study and the research team that worked together to the completion of the project. We acknowledge MicroResearch (www.microresearch.ca) for funding this project under research grant number 12 M MUS 02 and for mentoring support in drafting this article.

\section{Author details}

${ }^{1}$ Department of Psychiatry, Mbarara University of Science and Technology, Mbarara, Uganda. ${ }^{2}$ Department of Nursing, Mbarara University of Science and Technology, Mbarara, Uganda. ${ }^{3}$ Department of Community Health, Mbarara University of Science and Technology, Mbarara, Uganda. ${ }^{4}$ Department of Paediatrics, Psychiatry, Community Health and Epidemiology, Dalhousie University, Halifax, Canada.

Received: 4 July 2015 Accepted: 17 December 2015

Published online: 28 December 2015

References

1. Collins S. Changing the way we address severe malnutrition during famine. Lancet. 2001;358(9280):498-501.

2. Black RE, Allen LH, Bhutta ZA, Caulfield LE, de Onis M, Ezzati M, et al. Maternal and child undernutrition: global and regional exposures and health consequences. Lancet. 2008:371(9608):243-60.

3. De Onis M, Onyango AW, Borghi E, Garza C, Yang H. Comparison of the World Health Organization (WHO) Child Growth Standards and the National Center for Health Statistics/WHO international growth reference: implications for child health programmes. Public Health Nutr. 2006;9(07):942-7.

4. Pelletier DL, Frongillo EA. Changes in child survival are strongly associated with changes in malnutrition in developing countries. J Nutr. 2003;133(1): 107-19. 
5. Murray CJ, Lopez AD. Global mortality, disability, and the contribution of risk factors: Global Burden of Disease Study. Lancet. 1997;349(9063):1436-42.

6. Grantham-McGregor S, Cheung YB, Cueto S, Glewwe P, Richter L, Strupp B. Developmental potential in the first 5 years for children in developing countries. Lancet. 2007;369(9555):60-70.

7. Rayhan Ml, Khan MSH. Factors causing malnutrition among under five children in Bangladesh. Pak J Nutr. 2006;5(6):558-62.

8. Black MM, Baqui AH, Zaman K, El Arifeen S, Black RE. Maternal depressive symptoms and infant growth in rural Bangladesh. Am J Clin Nutr. 2009; 89(3):951S-7S

9. Surkan PJ, Kennedy CE, Hurley KM, Black MM. Maternal depression and early childhood growth in developing countries: systematic review and meta-analysis. Bull World Health Organ. 2011;89(8):607-15.

10. Rahman AIZ, Bunn J, Lovel H, Harrington R. Impact of maternal depression on infant nutritional status and illness: a cohort study. Arch Gen Psychiatry. 2004;61(9):946-52.

11. Fisher J, de Mello MC, Izutsu T. Pregnancy, childbirth and the postpartum period. Mental health aspects of women's reproductive health. 2009;8

12. Tronick ERC. Infants of depressed mothers. Harv Rev Psychiatry. 2009;17(2): 147-56.

13. Ovuga E, Boardman J, Wasserman D. The prevalence of depression in two districts of Uganda. Soc Psychiatry Psychiatr Epidemiol. 2005;40(6):439-45.

14. Harpham T, Huttly S, De Silva MJ, Abramsky T. Maternal mental health and child nutritional status in four developing countries. J Epidemiol Community Health. 2005:59(12):1060-4.

15. Uganda Bureau of Statistics. Uganda Demographic and Health Survey 2011. In. Edited by DHS M, International I, Calverton M, USA. Kampala, Uganda; 2012.

16. de Onis M. WHO child growth standards: length/height-for-age, weight-forage, weight-for-length, weight-for-height and body mass index-for-age. WHO; 2006.

17. Lohman T, Roche A, Martorell R. Anthropometric standardization reference manual. Champaign, Illinois: Human Kinetics; 1988.

18. Sheehan DV, Lecrubier $Y$, Sheehan $\mathrm{KH}$, Amorim $\mathrm{P}$, Janavs J, Weiller $\mathrm{E}$, et al. The Mini-International Neuropsychiatric Interview (M.I.N.I.): the development and validation of a structured diagnostic psychiatric interview for DSM-IV and ICD-10. J Clin Psychiatry. 1998;59 Suppl 20:22-33. quiz 34-57.

19. Patel V, Rahman A, Jacob KS, Hughes M. Effect of maternal mental health on infant growth in low income countries: new evidence from South Asia. BMJ. 2004;328(7443):820-3.

20. Rahman A, lqbal Z, Bunn J, Lovel H, Harrington R. Impact of maternal depression on infant nutritional status and illness: a cohort study. Arch Gen Psychiatry. 2004;61(9):946-52.

21. Patel V, Rahman A, Jacob KS, Hughes M. Effect of maternal mental health on infant growth in low income countries: new evidence from South Asia. BMJ. 2004;328(7443):820-3.

22. Nakimuli-Mpungu E, Odokonyero R, Laker J, Alderman S. Major Depression in Postconflict Northern Uganda: A Case Report. Am J Psychiatr. 2014;171(9):925-8.

23. Nakimuli-Mpungu E, Musisi S, Kiwuwa Mpungu S, Katabira E. Clinical presentation of bipolar mania in HIV-positive patients in Uganda. Psychosomatics. 2009;50(4):325-30.

24. Nakimuli-Mpungu E, Musisi S, Katabira E, Nachega J, Bass J. Prevalence and factors associated with depressive disorders in an HIV+ rural patient population in southern Uganda. J Affect Disord. 2011;135(1-3):160-7.

25. Akena D, Musisi S, Joska J, Stein DJ. The association between aids related stigma and major depressive disorder among HIV-positive individuals in Uganda. PLoS ONE. 2012;7(11), e48671.

26. Stewart RC. Maternal depression and infant growth-a review of recent evidence. Matern Child Nutr. 2007:3(2):94-107.

27. Rauh VA, Wasserman GA, Brunelli SA. Determinants of maternal child-rearing attitudes. J Am Acad Child Adolesc Psychiatry. 1990;29:375-81.

28. Hazarika A. The Effect of Maternal Education and Maternal Mental Health on Child's Growth. 2010

29. Murray L, Cooper P. Effects of postnatal depression on infant development. Arch Dis Child. 1997:77(2):99-101.

30. Anoop S, Saravanan B, Joseph A, Cherian A, Jacob K. Maternal depression and low maternal intelligence as risk factors for malnutrition in children: a community based case-control study from South India. Arch Dis Child. 2004;89(4):325-9.
31. Rahman A, Lovel H, Bunn J, lqbal Z, Harrington R. Mothers' mental health and infant growth: a case-control study from Rawalpindi, Pakistan. Child Care Health Dev. 2004;30(1):21-7.

32. Martins C, Gaffan E. Effects of early maternal depression on patterns of infant-mother attachment: a meta-analytic investigation. J Child Psychol Psychiatry. 2000;41(6):737.

33. Gwatkin D, Rutstein S, Johnson K, Pande R, Wagstaff A. Socio-economic differences in health, nutrition and poverty. HNP/Poverty Thematic Group of the World Bank Washington DC: The World Bank. 2000.

34. Reed BA, Habicht J-P, Niameogo C. The effects of maternal education on child nutritional status depend on socio-environmental conditions. Int J Epidemiol. 1996;25(3):585-92.

35. Makoka D. The impact of maternal education on child nutrition: evidence from Malawi, Tanzania, and Zimbabwe. Calverton, Maryland, USA: ICF International; 2013.

36. Kandala N-B, Madungu TP, Emina JB, Nzita KP, Cappuccio FP. Malnutrition among children under the age of five in the Democratic Republic of Congo (DRC): does geographic location matter? BMC Public Health. 2011;11(1):261.

37. Frost MB, Forste R, Haas DW. Maternal education and child nutritional status in Bolivia: finding the links. Soc Sci Med. 2005:60(2):395-407.

\section{Submit your next manuscript to BioMed Central and we will help you at every step:}

- We accept pre-submission inquiries

- Our selector tool helps you to find the most relevant journal

- We provide round the clock customer support

- Convenient online submission

- Thorough peer review

- Inclusion in PubMed and all major indexing services

- Maximum visibility for your research

Submit your manuscript at www.biomedcentral.com/submit 